\section{Earthkeeping: A Realization}

Last summer we took the first step toward implementation of Earthkeeping, a program of restoration-based public education being developed by the Society for Ecological Restoration in conjunction with the University of Wisconsin-Madison Arboretum, when the Arboretum acquired funding to take the first steps toward development of an Earthkeeping project in the watershed of Lake Wingra, a small, much abused lake, adjacent to the Arboretum.

This is a modest beginning - the funding provides for only a small-scale, pilot project-but it is a beginning. We have, moreover, several highly promising projects in planning stages of development, and by next summer we expect to have at least one of these underway. (Watch "SER News" for updates.)

With our Wingra Basin project just getting underway, however, it seems appropriate to devote this space to a brief description of Earthkeeping and the thinking behind it.

What is Earthkeeping? And why are we doing it?

Briefly, Earthkeeping is a program designed to provide opportunities for the public - that is, anyone and everyone-to participate in the work of ecological restoration as a way of learning about the natural landscape and developing a positive, intimate relationship with it.

The name, which we borrowed (with permission) from UW-Madison Environmental Studies Prof. Cal DeWitt, who published a book with the same name in 1980 (Eerdmans, Grand Rapids, MI), describes the program perfectly: it is an opportunity for people to become, quite literally, keepers and caretakers of the oikos, the planet and household we all inhabit.

It also, quite deliberately, refers to Earthwatch, the program that turns tourists into participants, and on which Earthkeeping is in certain respects modelled.

Participants in Earthwatch programs spend a few weeks working with researchers on an archeological dig, or surveying a population of a rare bird or animal; fees go to cover costs and also to contribute to the research program.

Earthkeeping will be like that, except that it will focus exclusively on restoration, and, though projects will certainly include research, the major emphasis will not be on research, but on restoration and education, with the overriding objective of learning how to put the two together.

Within these broad goals, Earthkeeping has several objectives, all related to exploring the implications of restoration as a model for a healthy relationship between ourselves and the rest of nature.

Through Earthkeeping, for example, we hope to explore the idea that restoration offers an ideal opportunity to learn about a natural landscape and our relationship with it - not only in a narrow, cognitive sense, but emotionally and physically as well, through the establishment of bonds, the making of memories and associations, and the acquisition of skills, habits and attitudes relevant to membership in the land community.
This is by no means a new idea. Its value has been clearly demonstrated through the work of SER members like Debbie Keammerer in Boulder, Colorado, or Steve Packard, Rich Reiner, and Tom Griggs through their work with Nature Conservancy volunteers in Illinois and California, and also by many teachers who have integrated restoration projects in schoolyards and local parks into their curricula.

One purpose of Earthkeeping is simply to capitalize on this experience, to develop this approach to environmental education, and to explore more systematically its value as a way of learning about and establishing a positive relationship with the natural landscape.

In the process we expect to help people to learn how ecosystems work (by working in them); how they influence nature (by influencing it); and how this influence can be good as well as bad (by bringing about an improvement in the landscape).

We also expect them to learn something about the process of restoration as well (by doing it), and to develop a better understanding of both its value and its limitations as a strategy for the conservation of natural areas.

Through Earthkeeping, we will also be exploring the idea of restoration as a performing art-that is an act that is expressive as well as effective-and also as a kind of alchemy, through which the initiate struggles to change dross into gold and in the process brings about deep-seated transformations in himself or herself.

If we can do this we think the appeal of this experience will prove irresistible, so that Earthkeeping will become a self-sustaining program and a perennial force both for restoration and for education in project areas.

Earthkeeping also reflects our faith in the idea that restoration and education - healing and learning - are part and parcel of the same process. This is an idea that has been weakened in recent years within medicine - a tragic mistake, and one we cannot afford to let happen in restoration, that most comprehensive of the healing arts, with its commitment not only to the healing of whole communities and ecosystems, but of whole people as well.

Earthkeeping will provide a model for this kind of comprehensive medical practice.

It will also provide a model for a new way of using natural areas such as national parks and wilderness areas - a way that liberates people from their role as tourists, observers, visitors, ultimately consumers, into roles as members and caretakers of the land community.

Beyond that, especially through locally oriented projects like the Wingra Basin project, it will provide opportunities for the ultimate vacation-a chance to stay at home and make the place you live better.

In this way we hope not only to increase public awareness of restoration, but to strike at what we believe to be the root of our "environmental" problems, which we believe is located somewhere back there in the human heart and the human mind. 